\title{
Stakeholder Engagement in Developing A Father- \\ Inclusive Early Life Obesity Prevention Intervention: First Heroes
}

\section{Santana R. Silver}

Harvard University T H Chan School of Public Health

Rachel Whooten ( $\square$ rwhooten@mgh.harvard.edu )

Massachusetts General Hospital https://orcid.org/0000-0002-6845-4821

\section{Gracia M. Kwete}

Massachusetts General Hospital for Children

Haley Farrar-Muir

Massachusetts General Hospital for Children

Rachel N. Cournoyer

Massachusetts General Hospital for Children

Elizabeth A. Barth

Massachusetts General Hospital for Children

Milton Kotelchuck

Massachusetts General Hospital for Children

\section{Elsie M. Taveras}

Massachusetts General Hospital for Children

\section{Research article}

Keywords: Fatherhood, Stakeholder Engagement, Community Engagement, Obesity Prevention, Social Determinants of Health, Maternal-Child Health, Perinatal Health, Infancy

Posted Date: October 27th, 2020

DOI: https://doi.org/10.21203/rs.3.rs-96185/v1

License: (a) (i) This work is licensed under a Creative Commons Attribution 4.0 International License. Read Full License 


\section{Abstract}

Background. Although paternal involvement in the perinatal period is associated with benefits for maternal-child health and reduced obesity risk, fathers are seldom included in perinatal or obesity prevention efforts. Engaging community leaders and fathers as stakeholders in intervention development is a critical step in designing a fatherinclusive intervention that is efficacious and responsive to their needs.

Methods. We conducted a structured engagement study, including community stakeholder engagement and qualitative interviews with new fathers, to inform the development of a prospective randomized controlled trial that includes mothers and fathers as equal partners in infant obesity prevention. We interpreted stakeholder feedback through the Consolidated Framework for Implementation Research (CFIR) framework.

Results. Between September 2019 and April 2020, we held a Community Engagement meeting, formed a Community Advisory Board, and conducted 16 qualitative interviews with new fathers. Stakeholder engagement revealed insights across CFIR domains including intervention characteristics (relative advantage, complexity, design quality \& packaging), outer setting factors (cosmopolitanism and culture), individual characteristics (including self-efficacy, state of change, identification with the organization) and process (engagement and adaptation). Stakeholders discussed the diverse challenges and rewards of fatherhood, as well as the intrinsic paternal motivation to be a loving, supportive father and partner. Both community leaders and fathers emphasized the importance of tailoring program delivery and content to meet specific parental needs, including a focus on the social-emotional needs of new parents.

Conclusions. A structured process of multidimensional stakeholder engagement was successful in improving the design of a father-inclusive perinatal obesity prevention interventions. Father engagement was instrumental in both reinforcing community ties and increasing our understanding of fathers' needs, resulting in improvements to program values, delivery strategies, personnel, and content. This study provides a practical approach for investigators looking to involve key stakeholders in the pre-implementation phase of intervention development.

Trial registration: ClinicalTrials.gov, NCT04477577. Registered 20 July 2020, https://clinicaltrials.gov/ct2/show/NCT04477577

\section{Plain Language Summary}

While fathers play a key role in the health of both mothers and infants, most research studies on early childhood health only target mothers. We planned to adapt an early life obesity prevention program to include mothers and fathers as equal participants. To develop this program, we worked with new fathers and community leaders to identify their opinions on what this program should include. This feedback was important in improving our program design. Our process of working with our stakeholders also provides an example for other researchers who would like to engage participants in designing research programs.

\section{Introduction}

Childhood obesity is a major public health concern, with over $10 \%$ of two-to-five-year-old children in the United States meeting criteria for obesity and higher rates among children from racial/ethnic minorities and low-income families $(1,2)$. Disparities in obesity prevalence originate before birth and are exacerbated by risk factors during infancy and early childhood, which influence health outcomes across the life course (3). While early life obesity 
interventions are a promising strategy for obesity prevention (4), the majority target mothers and largely ignore the important role of fathers $(5,6)$.

Paternal engagement in early life is associated with positive maternal-infant health outcomes (7-9) and overall child well-being (10), as well as decreased childhood obesity risk $(11,12)$. Despite this, barriers at multiple levels prevent adequate outreach and engagement of fathers in early life programming (13). These barriers include both inner setting factors, such as lack of conceptual engagement, inadequate father-focused program materials and lack of trained staff to work with fathers, as well as outer setting factors, such as insufficient funding and lack of established best practices. On a larger scale, there is also the need for a cultural shift in recognizing the importance of fathers as partners in parenting. To overcome these obstacles and meaningfully involve fathers in early life interventions, engaging key stakeholders - especially fathers - is a critical strategy to inform the design and implementation of an efficacious program that are responsive to their unique needs, perspectives, and experiences $(14,15)$.

The purpose of this engagement study was to engage both fathers and community stakeholders to inform the adaptation of the "First 1,000 Days" intervention, an evidence-based, systems-level obesity prevention program that originally targeted the mother-infant dyad, to actively and fully involve fathers (16). In planning for a new, fatherinclusive intervention, we conducted a structured multilevel engagement study to identify strategies to recruit, retain, and influence fathers in perinatal and obesity prevention programs. We used the Consolidated Framework for Implementation Research (CFIR), an evidence-based framework that identifies multi-level intervention factors that influence implementation effectiveness, to interpret stakeholder feedback (17).

Our goal was to engage and learn from fathers themselves, applying their lived experiences to identify and dismantle traditional barriers preventing father engagement in the perinatal period. Through strengthening our program to meet the needs of fathers, our long-term aim is to empower fathers in promoting strategies for preventing childhood obesity. Advancing the development of informed father-inclusive perinatal programs, we hope our program can serve as a practical model for other groups that seek to incorporate both parents equally in traditionally maternally oriented spaces (18). This manuscript describes the process and results of our stakeholder engagement.

\section{Methods}

Over an 8-month period (September 2019 - May 2020), we engaged a broad range of stakeholders in the adaptation of the First 1,000 Days program to be father-inclusive. Our engagement efforts informed the design of a prospective randomized controlled trial, First Heroes, enrolling the mother-father-infant triad, beginning in pregnancy and continuing throughout the first year of life.

Our engagement plan consisted of two components: community stakeholder engagement and qualitative interviews with new fathers. We chose each component to provide unique perspectives relating to issues such as father receptivity to program participation, study design, and intervention structure and content. Based on our prior work with First 1,000 Days, we also recognized that embedding our intervention within the larger community and gaining institutional support is critical for increasing the likelihood of intervention success (16).

\section{Setting}


We directed our engagement efforts to include fathers and clinical leaders who receive and provide care at obstetric and pediatric practices affiliated with Massachusetts General Hospital in Boston, Massachusetts. Massachusetts General Hospital includes hospital- and community-based care locations and serves a diverse population, with over $40 \%$ of delivering mothers identifying as a racial or ethnic minority. We aimed for our engagement sample to reflect this diversity. We also engaged community leaders with experience in engaging new parents, especially fathers, in early life interventions and connecting families with community resources.

\section{Community Stakeholder Engagement}

We conducted a two-stage process of community engagement. We held the open Community Engagement Meeting to introduce the study to community stakeholders. Following the meeting, interested attendees were invited to participate in a Community Advisory Board to provide ongoing input.

\section{Community Engagement Meeting}

We held an open Community Engagement Meeting (CEM) in September 2019 to guide the initial formative stages of intervention adaptation. In identifying meeting invitees, we leveraged existing community connections from the First 1,000 Days, as well as solicited requests from these connections to identify any other key stakeholders we may have overlooked. We systematically created an invite list, including representatives from Massachusetts General Hospital obstetric and pediatric clinical leadership as well as community home visiting programs, father advocacy groups, and local fathers. During this meeting, we provided an update on results from First 1,000 Days(19), explained our rationale in extending the program to include fathers, and described the current proposed intervention structure (Table 1).

\section{Community Advisory Board}

We invited CEM attendees to provide ongoing feedback through participation in our Community Advisory Board (CAB). We informed potential members that responsibilities would include (1) attending quarterly meetings and (2) providing feedback on intervention design and content. We asked members to identify other stakeholders within the fatherhood community for invitation. The first CAB meeting was held in January 2020. The meeting agenda addressed program modifications based on initial feedback, recruitment plans, and study educational materials. Board members received all study materials prior to the meeting for their review, with opportunities for feedback provided within the meeting as well as through follow-up phone conversations or written communication. The first meeting was held via video conference. To minimize the burden on our Advisory Board Members during the COVID pandemic, we provided ongoing updates through email (Spring-Summer 2020), with resumption of the quarterly meeting schedule in Fall 2020.

\section{Qualitative Interviews}

\section{Study Design}

We conducted 16 semi-structured qualitative interviews (November 2019-April 2020) with fathers of children under 1 year old to investigate the acceptability and feasibility of the proposed intervention. We identified fathers for participation through review of well-child visits with pediatric practices at Massachusetts General Hospital, including both hospital- and community-based locations. Fathers were eligible to participate if they were at least 18 years old, had a child receiving care at a MGH pediatric primary care site, were English proficient, were first time 
fathers, and had a child 0-12 months without significant medical comorbidities that would affect growth, development, and feeding. This study was approved by the MassGeneral Brigham Institutional Review Board.

\section{Interview Procedures}

Study staff mailed recruitment letters to eligible fathers describing the engagement study. One week after the letters were mailed, study staff contacted fathers by phone to explain the study, answer questions, and enroll fathers who chose to participate. Three phone call attempts were made to reach each eligible father who received a letter. We called 137 fathers; 83 did not answer the phone, 17 declined, 21 were ineligible ( $n=8$ due to language barriers, $n=2$ due to medical comorbidities, $n=3$ due to child age $>12$ months, $n=2$ due to moving out of state, and $n=6$ due to not being a first time father), and 16 consented to participation. Participants received a $\$ 25 \mathrm{gift}$ card upon interview completion. After providing informed consent, fathers participated in semi-structured, in-depth interviews. The development of the interview guide was informed by a review of prior studies exploring early life obesity prevention strategies (4) and literature review of relevant methodological considerations regarding father engagement $(13,20-22)$ as well as CFIR constructs (17). The interview guide included core and probing questions to elicit discussion of relevant topics, such as fathers' information and resource needs, perceptions of their roles and experiences, and preferences for intervention content and modalities. Each semi-structured 30-minute phone interview was audiotaped and transcribed by an independent company for analysis. We reached thematic saturation with a total of 16 interviews, as review of transcripts revealed reinforcement of previously identified themes and no new themes were generated.

\section{Data Analysis}

We used the CFIR domains to organize feedback from community stakeholders as well as our thematic analysis of qualitative father interviews (17). Two team members (RW, SS) organized stakeholder perceptions into relevant CFIR domains, including (1) characteristics of the intervention, relating to intervention advantages versus alternative solutions (relative advantage), potential implementation difficulties (complexity), and intervention design (design quality and packaging), (2) "outer setting" factors, relating to connections with other organizations (cosmopolitanism), (3) "inner setting" characteristics of the organization implementing the intervention, including norms and values (culture), and (4) characteristics of individuals involved in the intervention, including progress towards sustained intervention use (state of change), commitment to the program (identification), beliefs that they are capable of executing the intervention (self-efficacy), and other personal traits of both intervention participants and intervention staff (other attributes).

\section{Community Stakeholder Meetings}

At both the community engagement meeting (CEM) and advisory board (AB) meeting, a research team member transcribed detailed notes of all feedback provided by meeting attendees. We reviewed findings in detail in group debrief meetings following both stakeholder meetings. We categorized transcribed notes into CFIR domains as described above.

\section{Qualitative Interview}

We used an iterative immersion-crystallization approach to conduct content analysis through repeated cycles of reading and discussing transcripts to identify predominant themes (23). The full analysis team (HFM, RW, GK, MK, ET) individually read nine transcripts in-depth in sets of three before discussing as a group. Based on our initial list of themes, three team members (HFM, RW, GK) independently coded interview content line-by-line, collating codes 
into an Excel spreadsheet to generate a preliminary codebook. We reviewed independent coding for consensus between coders. We revised and reviewed the codebook after each set of three interviews.

After in-depth review of nine interviews with the full analysis team, we noted overall repetition of themes. We reviewed the codebook at this time, reorganizing all codes under relevant corresponding themes that had been identified through group discussion. Two coders (SS, RW) independently coded the next two interviews using the revised codebook, with agreement $>85 \%$. The final five interviews were independently coded, with no new themes emerging from content review and discussion.

\section{Results}

\section{Stakeholder Characteristics}

For the Community Engagement Meeting (CEM), we invited 46 individuals to attend, representing Massachusetts General Hospital obstetric, pediatric, and research leadership $(n=18)$, obstetric and pediatric clinical champions ( $\mathrm{n}$ $=4$ ), local community and state programs focused on fatherhood or early childhood health $(n=17)$, community outreach/home visiting programs $(n=3)$, and fathers who were community leaders $(n=4)$. Ultimately, 22 invitees planned to attend and 11 attended; of those unable to attend, the primary reason was scheduling conflicts. Our Community Advisory Board (CAB) advisory board was primarily drawn from CEM meeting attendees and was composed of 12 members, including representatives from pediatrics and obstetrics $(n=2)$, academic public health research $(n=1)$, community outreach/home visiting $(n=2)$, local family and community organizations $(n=4)$, state public health infrastructure $(n=1)$, and a national child health organization $(n=1)$ as well as a local father advocate $(n=1)$.

A total of 16 fathers completed the qualitative interview, with 8/16 receiving pediatric care at a community health center. Of participating fathers, 10/16 identified as white, 3/16 identified as Hispanic/Latino, and 3/16 identified as "other". The majority of fathers had a college education or higher (10/16); the remainder had either completed high school/GED $(n=2)$ or some college $(n=4)$. The median age of participating fathers was 35 years (IQR: 32, 39).

\section{Stakeholder Feedback}

We present results through the five CFIR domains (intervention characteristics, outer setting, inner setting, individual characteristics, and process). Within each of these domains, we organize findings from community stakeholder meetings and qualitative interviews by mapping emerging themes to relevant CFIR constructs.

\section{Intervention Characteristics: key intervention attributes that influence implementation effectiveness}

Relative Advantage:perceived advantages of intervention relative to alternatives. At the CEM, attendees highlighted advantages that are unique to our intervention, including program initiation during pregnancy, specific outreach to fathers, and aim to empower both parents. Within the qualitative interviews, fathers identified several relative advantages of our proposed intervention, including convenient delivery of father-specific intervention content (Table 2).

Complexity:perceived difficulty of implementation. CEM attendees and CAB members reflected on ways in which the intervention must address the more complex sociocultural needs of a socioeconomically and racially diverse patient population such as through accommodating busy work schedules and training interventional personnel on cultural sensitivities and mandatory reporting (Table 1). Fathers identified several potential implementation barriers 
related to program delivery and content, such as scheduling conflicts, disagreement with content, technological difficulties, and intrusiveness of home visits (Table 2).

Design Quality and Packaging: how well the intervention is presented, bundled, and assembled. To brand the program in a way that immediately engages fathers, CEM attendees suggested an inclusive name for the program, with an emphasis on the theme of parents as 'heroes.' With regards to visit modality and delivery mode, both $\mathrm{CAB}$ members and fathers preferred home visits to virtual visits and recommended presenting intervention content in 'bite-sized' summaries before and after visits (Tables 1,2). Both groups also recommended a degree of customization depending on dyads' preferences.

Though we initially designed the visit structure and timing to align with critical developmental time points during the prenatal and postnatal periods, there were mixed attitudes amongst interviewees regarding the timing of each visit with respect to the pregnancy and child's age as well as the overall structure of the proposed intervention (Table 1). CEM attendees, CAB members, and father interviewees generally supported the proposed intervention content. Stakeholders also proposed key content areas that they felt were important to include and highlight in the program curriculum, such as infant growth and development, as well as parental support for social connectedness, relationships, and mental health (Table 1).

\section{Outer Setting: factors external to the organization implementing the intervention}

Cosmopolitanism: the overall connectedness with other organizations. To take advantage of existing resources that support new parents, , CEM attendees recommended connecting participants with local parenting, fatherhood, and child abuse prevention programs. Similarly, CAB members provided recommendations to relevant parenting and child development resources from national organizations, such as the National Institute for Children's Health Quality (24), and local organizations, such as Boston Basics (25).

\section{Inner Setting: characteristics of the organization implementing the intervention}

Culture: the organization's norms, values, and assumptions. CEM attendees urged us to promote an internal culture that expects dads to be involved, thereby motivating fathers to participate in the intervention. Intervention activities should reinforce the value that dads are important in their children's lives. CEM attendees also suggested including ways to show new fathers that they are not alone, such as through testimonials from other fathers and/or connecting fathers in support groups.

\section{Characteristics of Individuals: qualities of individuals involved in the program}

\section{Participants}

Individual State of Change:individuals' progress towards enthusiastic and sustained use of the intervention. CEM attendees cautioned that many of our potential participants may not yet fully understand what it means to be a parent and may have lacked parenting role models within their own lives. As such, a goal of our project is to empower new parents in understanding their roles, moving them into a higher "state of readiness" to evolve to meet the needs of being a parent.

Identification with the organization:individuals' relationship and commitment to an organization. CEM attendees highlighted the importance of building genuine relationships between the coaching team and parents. Strong 
relationships between the home visitor and fathers will cultivate trust and keep the father engaged throughout the intervention.

Knowledge/beliefs about the intervention: individuals' value placed on intervention. Father interviewees recognized a need for the proposed intervention (Table 3). Despite the diverse sources that dads-to-be draw on for support and advice, including family, clinicians, friends, and published information, the information they receive is often unclear, contradictory, and explicitly directed at mothers. Consequently, fathers discussed feeling largely unprepared with the information and skills necessary to support their babies and partners. Sleep disturbance and constant work were cited as the most physically draining aspects of being a new father. Emotionally draining challenges included the uncertainty and novelty of fatherhood, feeling of helplessness, relationship strain with the mother, and baby colic.

Self-efficacy: individuals' belief in capacity to achieve implementation goals. CEM attendees spoke to the importance of messaging that fathers can make a difference in their children's health. Supporting this theme, attendees framed fathers as "heroes", suggesting that "all men want to be heroes to their child...if you include them, they will rise to this level." Fathers bolstered the notion of self-efficacy, emphasizing the intrinsic motivation to provide for their child and partner (Table 3).

Personal attributes: traits of participating individuals. Within the CEM, attendees raised concern about the intervention inadvertently excluding certain demographic groups (Table 1). Fathers discussed ways in which the physical and mental strain of fatherhood adversely affect their personal health and the difficulties they faced in maintaining healthy self-care habits during the postnatal period. Highly relevant to the intervention and addressing these challenges is fathers' perceptions regarding their main parenting roles and the importance of these roles (Table 3).

\section{Intervention Personnel}

Personal attributes: CEM attendees and CAB members provided suggestions on optimal skills and credentials we should seek in intervention staff, including sociodemographic diversity and a balance of social skills and personality traits with appropriate educational background, training, and supervision (Table 1). However, CAB members cautioned against too stringent educational requirements, as this may be a barrier for finding well-suited candidates from the community. Fathers were generally open to a variety of messengers relating to their child's health, being a father, and their own health (Table 1).

\section{Process: critical stages of program implementation}

\section{Engaging: involving appropriate individuals in the implementation and use of the program.}

Champions (individuals who support program implementation): To support recruitment efforts in hiring a health coach, CAB members recommended leveraging both local professional and community organizations to advertise the position and utilizing a community health worker model to address potential qualification barriers for applicants (Table 1).

Innovation participants (individuals who participate in the program): CEM attendees discussed the importance of engaging fathers directly through addressing their backgrounds, "meeting them where they are". They suggested several outreach strategies to achieve this (Table 1). Fathers recommended a range of additional facilitators to 
recruitment and engagement maintenance (Table 1). Fathers also underscored the importance of adaptability (degree that an intervention can be modified to individual needs) (Table 2).

\section{Discussion}

In the pre-implementation phase of the First Heroes randomized controlled trial, we used a structured process of multidimensional stakeholder engagement to adapt a mother-focused perinatal obesity prevention intervention to include fathers as equal participants. This process was instrumental in reinforcing community ties and increasing our understanding of fathers' needs, strengthening our intervention to deeply engage fathers throughout the entire process. CFIR provided a framework for understanding and applying our stakeholders' feedback. Our process demonstrated the value of including multiple perspectives when engaging stakeholders, as community leaders and new fathers provided insights that were both unique as well as mutually reinforcing.

While we were open to significant changes in our overall design based on feedback, our stakeholders instead highlighted key areas of focus that strengthened our planned intervention. Stakeholder input influenced our intervention values, delivery strategies, personnel, and content. Both community stakeholders and new fathers had strong support for our approach, citing the advantage of and need for parenting programs that include fathers and begin during pregnancy.

Our community stakeholders encouraged an inclusive culture that engages fathers from the start. We named our program First Heroes, uniting the preceding First 1,000 Days intervention with themes that arose in the CEM. Community stakeholders strongly believed fathers would rise to the expectations set for them. This was reinforced by the fathers we interviewed who spoke freely and candidly about the rewards and challenges of fatherhood, as well as interest in our program, as long as it was responsive to their needs.

Stakeholder engagement also influenced our program delivery strategies. We took feedback into account as we decided to allow participant preference to determine both visit type as well as options for receiving materials. We created materials that could be disseminated through print, email, text messaging, and videos, in addition to the choice of virtual versus home health coach visits.

Our community stakeholders emphasized essential qualities for the individual delivering our intervention, namely compassion and 'soft' skills that might not be able to be taught. Fathers demonstrated overall flexibility in who they would trust for advice, reinforcing that individual qualities were more important than objective characteristics. We responded to this by creating a health coaching "team," including a social worker, dietitian, and an experienced health coach, one of whom was male.

Working with stakeholders across multiple dimensions provided unique insights for our intervention content. Community stakeholders were more attuned with 'outer setting' resources to integrate into and support our intervention, as well as the need for awareness of the impact of social determinants of health on infant and parent wellbeing. Fathers were more concrete about their needs, especially related to parenting education related to sleep, feeding, development, and sickness. Both agreed on the importance of the social and emotional needs of new parents, which we made a priority in our intervention content.

While the primary aim of our engagement work was to inform the development of an obesity prevention intervention that equally engages mothers and fathers, obesity prevention themes were seldom explicitly discussed among any of our stakeholders. Despite this, targets for obesity prevention were frequent topics of discussion. 
Fathers identified feeding their child and promoting healthy growth as a key role, which the literature supports as key roles for fathers (26). Additionally, new fathers endorsed the challenges of maintaining their own healthy sleep, nutrition, and physical activity habits after becoming a father, all of which are potentially obesogenic behaviors. Lastly, community stakeholders emphasized the importance of social determinants of health as a foundational target for our intervention. This resonates with an equity approach to obesity prevention, which requires consideration of basic needs and societal inequities as an essential first step (27). Our engagement efforts and success in eliciting these priorities represent a model for engaging fathers in the development of perinatal and obesity prevention efforts.

\section{Limitations}

While we attempted to recruit a diverse sample through outreach within the community health centers, we unfortunately were not able to logistically conduct interviews in Spanish due to the costs of translating transcribed interviews. As a result, our sample was relatively homogenous with regard to race/ethnicity and educational background. However, even within this sample, fathers identified a great need for resources and father outreach. Feedback from our community stakeholders was critical in providing a voice for the fathers and families they work with, who we were unable to engage through more traditional research methods.

Given existing literature that highlights struggles with recruiting fathers to participate in research, we used active strategies, as opposed to passive methods, for recruitment. Despite our multifaceted strategy with both mailed and phone outreach, we were unable to reach the majority of eligible fathers. We hypothesize that this does not demonstrate a lack of interest but instead reflects the challenge of identifying effective routes to reach fathers.

Our own experiences in recruiting fathers for this engagement study will inform our future recruitment efforts for the First Heroes study. Additionally, our engagement efforts highlighted the need for feedback from a more diverse group of fathers. We will continue to prioritize understanding our participants' experiences as we implement our intervention. Implementation science methods, such as CFIR, provide resources for informing the translation of research findings into practice and we intend to continue this participant-engaged approach throughout our work.

Notably, our engagement process overlapped with the early stages of the COVID19 pandemic, which resulted in shifting priorities for new fathers as well as our advisory board members. We had limited success in recruiting fathers for interviews after the onset of the pandemic, and our advisory board members had new responsibilities in responding to the crisis. While we had planned to increase the presence of fathers within our advisory board, as well as the diversity of fathers within our interview sample, our target population included communities who were most impacted by the pandemic at that time. We will continue to prioritize outreach to this group through our continued work.

Given the pandemic, in-person health coach visits were no longer possible, and we moved all interactions (including recruitment) to virtual. Our initial advice from our advisory board to focus on social determinants of health became more salient following COVID19. The challenges associated with COVID19 reinforced our efforts to address social needs in our intervention through appropriate community-based referrals.

\section{Conclusion}

Through our engagement process, we identified significant benefits for multidimensional stakeholder involvement. This engagement study gave voice to fathers throughout the design of an intervention in a perinatal health area

Page $10 / 21$ 
that does not traditionally include them. Using a structured framework with CFIR allowed us to meaningfully improve our intervention, specifically relating to values, delivery, personnel, and content. Recognizing the value of stakeholder engagement, we will continue talking to and learning from fathers throughout subsequent phases of the First Heroes program in an iterative process that incorporates fathers in the fight against childhood obesity. Our work provides a practical model for other investigators in designing and adapting interventions to new populations, especially those overlooked through traditional research initiatives.

\section{Declarations}

Ethics approval and consent to participate: The MassGeneral Brigham Institutional Review Board completed the ethical review and approved this project.

Consent for publication: Not applicable.

Availability of data and materials: The datasets used and/or analyzed during the current study are available from the corresponding author on reasonable request.

Competing interests: The authors have no individual conflicts of interest to report.

Funding: This study was supported by the Health Resources and Services Administration (HRSA) of the U.S. Department of Health and Human Services (HHS) as part of an award totaling $\$ 900,000$ with zero percentage financed with nongovernmental sources (Grant \#R40MC32753). The sponsors had no role in the study design; collection, analysis and interpretation of data; writing of report; or decision to submit for publication.

Authors' contributions: Interviews were coded by RW, HFM, and GK. They were analyzed by HFM, RW, GK, MK, and ET. SS and RW both organized stakeholder perceptions into relevant CFIR domain, and were major contributors in writing the manuscript. All authors read and approved the final manuscript.

Acknowledgements: Not applicable.

\section{Conflict of interest statement:}

This project is supported by the Health Resources and Services Administration (HRSA) of the U.S. Department of Health and Human Services (HHS) as part of an award totaling $\$ 900,000$ with zero percentage financed with nongovernmental sources under the Maternal and Child Health Field-Initiated Research Program (Grant \#R40MC32753). The contents are those of the authors and do not necessarily represent the official views of, nor an endorsement, by HRSA, HHS or the U.S. Government.

The authors have no individual conflicts of interest to report.

\section{References}

1. Hales CM, Carroll MD, Fryar CD, Ogden CL. Prevalence of Obesity Among Adults and Youth: United States, 2015-2016. Hyattsville, MD; 2017. Contract No.: No. 288.

2. Ogden CL CM, Fakhouri TH, et al. Prevalence of Obesity Among Youths by Household Income and Education Level of Head of Household - United States 2011-2014. MMWR Morb Mortal Wkly Rep. 2018;67:186-9. 
3. Woo Baidal JA, Locks LM, Cheng ER, Blake-Lamb TL, Perkins ME, Taveras EM. Risk Factors for Childhood Obesity in the First 1,000 Days: A Systematic Review. Am J Prev Med. 2016;50(6):761-79.

4. Blake-Lamb TL, Locks LM, Perkins ME, Woo Baidal JA, Cheng ER, Taveras EM. Interventions for Childhood Obesity in the First 1,000 Days A Systematic Review. Am J Prev Med. 2016;50(6):780-9.

5. Morgan PJ, Young MD, Lloyd AB, Wang ML, Eather N, Miller A, et al. Involvement of Fathers in Pediatric Obesity Treatment and Prevention Trials: A Systematic Review. Pediatrics. 2017;139(2).

6. Davison KK, Kitos N, Aftosmes-Tobio A, Ash T, Agaronov A, Sepulveda M, et al. The forgotten parent: Fathers' representation in family interventions to prevent childhood obesity. Prev Med. 2018;111:170-6.

7. Alio AP, Kornosky JL, Mbah AK, Marty PJ, Salihu HM. The impact of paternal involvement on feto-infant morbidity among Whites, Blacks and Hispanics. Matern Child Health J. 2010;14(5):735-41.

8. Surkan PJ, Dong L, Ji Y, Hong X, Ji H, Kimmel M, et al. Paternal involvement and support and risk of preterm birth: findings from the Boston birth cohort. J Psychosom Obstet Gynaecol. 2019;40(1):48-56.

9. Redshaw M, Henderson J. Fathers' engagement in pregnancy and childbirth: evidence from a national survey. BMC Pregnancy Childbirth. 2013;13:70.

10. Sarkadi A, Kristiansson R, Oberklaid F, Bremberg S. Fathers' involvement and children's developmental outcomes: a systematic review of longitudinal studies. Acta Paediatr. 2008;97(2):153-8.

11. Freeman E, Fletcher R, Collins CE, Morgan PJ, Burrows T, Callister R. Preventing and treating childhood obesity: time to target fathers. Int J Obes (Lond). 2012;36(1):12-5.

12. Wong MS, Jones-Smith JC, Colantuoni E, Thorpe RJ, Jr., Bleich SN, Chan KS. The Longitudinal Association Between Early Childhood Obesity and Fathers' Involvement in Caregiving and Decision-Making. Obesity (Silver Spring). 2017;25(10):1754-61.

13. Davison KK, Gavarkovs A, McBride B, Kotelchuck M, Levy R, Taveras EM. Engaging Fathers in Early Obesity Prevention During the First 1,000 Days: Policy, Systems, and Environmental Change Strategies. Obesity (Silver Spring). 2019;27(4):525-33.

14. Frank L, Forsythe L, Ellis L, Schrandt S, Sheridan S, Gerson J, et al. Conceptual and practical foundations of patient engagement in research at the patient-centered outcomes research institute. Qual Life Res. 2015;24(5):1033-41.

15. Fleurence R, Selby JV, Odom-Walker K, Hunt G, Meltzer D, Slutsky JR, et al. How the Patient-Centered Outcomes Research Institute is engaging patients and others in shaping its research agenda. Health Aff (Millwood). 2013;32(2):393-400.

16. Blake-Lamb T, Boudreau AA, Matathia S, Tiburcio E, Perkins ME, Roche B, et al. Strengthening integration of clinical and public health systems to prevent maternal-child obesity in the First 1,000Days: A Collective Impact approach. Contemp Clin Trials. 2018;65:46-52.

17. Damschroder LJ, Aron DC, Keith RE, Kirsh SR, Alexander JA, Lowery JC. Fostering implementation of health services research findings into practice: a consolidated framework for advancing implementation science. Implement Sci. 2009;4:50.

18. Woolf SH, Zimmerman E, Haley A, Krist AH. Authentic Engagement Of Patients And Communities Can Transform Research, Practice, And Policy. Health Aff (Millwood). 2016;35(4):590-4.

19. Blake-Lamb T, Boudreau AA, Matathia S, Perkins ME, Roche B, Cheng ER, et al. Association of the First 1,000 Days Systems-Change Intervention on Maternal Gestational Weight Gain. Obstet Gynecol. 2020;135(5):104757. 
20. Alio AP, Bond MJ, Padilla YC, Heidelbaugh JJ, Lu M, Parker WJ. Addressing policy barriers to paternal involvement during pregnancy. Matern Child Health J. 2011;15(4):425-30.

21. Vollmer RL, Adamsons K, Mobley AR. Recruitment, Engagement, and Retention of Fathers in Nutrition Education and Obesity Research. J Nutr Educ Behav. 2019;51(9):1121-5.

22. Lee JY, Knauer HA, Lee SJ, MacEachern MP, Garfield CF. Father-Inclusive Perinatal Parent Education Programs: A Systematic Review. Pediatrics. 2018;142(1).

23. Borkan J. Immersion/Crystallization. In: Crabtree B MW, editor. Doing Qualitative Research. Thousand Oaks, CA: Sage Publications; 1999.

24. Quality NIfCsH. [Available from: https://www.nichq.org.

25. Basics TB. Boston Basics [cited 2020. Available from: https://boston.thebasics.org.

26. Khandpur N, Blaine RE, Fisher JO, Davison KK. Fathers' child feeding practices: a review of the evidence. Appetite. 2014;78:110-21.

27. Kumanyika SK. A Framework for Increasing Equity Impact in Obesity Prevention. Am J Public Health. 2019;109(10):1350-7.

\section{Tables}

Table 1: Specific Stakeholder Feedback in Relation to Initial “First Heroes” Intervention Protocol Design 


\begin{tabular}{|c|c|c|c|c|c|}
\hline & \multirow[t]{2}{*}{ Topic } & \multirow{2}{*}{$\begin{array}{l}\text { Initial Protocol } \\
\text { Design }\end{array}$} & \multicolumn{3}{|l|}{ Stakeholder Feedback } \\
\hline & & & CEM & $C A B$ & Interviews \\
\hline \multirow[t]{2}{*}{ Recruitment } & $\begin{array}{l}\text { Program } \\
\text { branding }\end{array}$ & $\begin{array}{l}\text { "First } 1000 \text { Days } \\
\text { Fatherhood } \\
\text { Intervention"; } \\
\text { obesity } \\
\text { prevention } \\
\text { initiative }\end{array}$ & $\begin{array}{l}\text { Suggested } \\
\text { "HEROES" name to } \\
\text { capture the } \\
\text { important/ inclusive } \\
\text { role of fathers. }\end{array}$ & $\mathrm{N} / \mathrm{A}$ & $\mathrm{N} / \mathrm{A}$ \\
\hline & $\begin{array}{l}\text { Eligibility } \\
\text { Criteria }\end{array}$ & $\begin{array}{l}\text { First time } \\
\text { biological } \\
\text { mother-father } \\
\text { dyad, >18 yo, } \\
\text { English/Spanish } \\
\text { speaking, intent } \\
\text { to continue care } \\
\text { at MGH obstetric } \\
\text { and pediatric } \\
\text { practice }\end{array}$ & $\begin{array}{l}\text { Concern for } \\
\text { excluding certain } \\
\text { demographic } \\
\text { groups (i.e. } \\
\text { single/separated } \\
\text { parents and same- } \\
\text { sex couples) }\end{array}$ & $\mathrm{N} / \mathrm{A}$ & $\mathrm{N} / \mathrm{A}$ \\
\hline \multirow[t]{7}{*}{$\begin{array}{l}\text { Intervention } \\
\text { Design }\end{array}$} & \multirow[t]{4}{*}{ Staffing } & \multirow[t]{4}{*}{$\begin{array}{l}\text { Research nurse } \\
\text { or Health Coach, } \\
\text { supplemented } \\
\text { by pediatrician } \\
\text { and research } \\
\text { assistant }\end{array}$} & $\begin{array}{l}\text {-Staff team with } \\
\text { sociodemographic } \\
\text { diversity } \\
\text {-Adequate } \\
\text { educational } \\
\text { backgrounds }\end{array}$ & $\begin{array}{l}\text {-Train on } \\
\text { cultural } \\
\text { sensitivities } \\
\text { and } \\
\text { mandatory } \\
\text { reporting }\end{array}$ & $\begin{array}{l}\text { Fathers open to a } \\
\text { variety of different } \\
\text { messengers to } \\
\text { receive } \\
\text { information } \\
\text { relating to: }\end{array}$ \\
\hline & & & $\begin{array}{l}\text {-Social } \\
\text { skills/personality } \\
\text { traits (non- } \\
\text { judgmental, }\end{array}$ & $\begin{array}{l}\text {-Pair (1) } \\
\text { research } \\
\text { nurse with } \\
\text { academic } \\
\text { experience }\end{array}$ & $\begin{array}{l}\text {-Their child's } \\
\text { health: trusted } \\
\text { pediatrician }(n=6) \text {, } \\
\text { their partner }(n=3) \text {, } \\
\text { then family }(n=2)\end{array}$ \\
\hline & & & $\begin{array}{l}\text { empathetic, flexible, } \\
\text { trusting) } \\
\text {-Not necessary to } \\
\text { be healthcare } \\
\text { professional but } \\
\text { adequate } \\
\text { training/supervision }\end{array}$ & $\begin{array}{l}\text { health coach } \\
\text { with } \\
\text { community } \\
\text { and } \\
\text { parenting } \\
\text { experience to } \\
\text { provide well- } \\
\text { rounded }\end{array}$ & $\begin{array}{l}\text {-Being a father: } \\
\text { trusted other } \\
\text { fathers }(n=4) \text {, } \\
\text { pediatrician }(n=2) \text {, } \\
\text { their own parents } \\
(n=2) \text {, then family } \\
(n=1) \text { and peers } \\
(n=1)\end{array}$ \\
\hline & & & $\begin{array}{l}\text {-Active role models } \\
\text { (males and fathers) }\end{array}$ & $\begin{array}{l}\text { delivery } \\
\text { experience }\end{array}$ & $\begin{array}{l}\text {-Their own health: } \\
\text { trusted physician } \\
\text { or another } \\
\text { healthcare } \\
\text { professional } \\
(n=4) \text {, then peers } \\
(n=2) \text { and family } \\
(n=2)\end{array}$ \\
\hline & \multirow[t]{3}{*}{ Content } & \multirow{3}{*}{$\begin{array}{l}\text {-Responsive } \\
\text { parenting } \\
\text {-Parent lifestyle } \\
\text { behaviors } \\
\text {-Access to } \\
\text { resources/Social } \\
\text { Determinants of } \\
\text { Health }\end{array}$} & $\begin{array}{l}\text {-Growth and } \\
\text { developmental } \\
\text { milestones }\end{array}$ & \multirow{2}{*}{$\begin{array}{l}\text {-Substance } \\
\text { abuse } \\
\text { information } \\
\text { in relation to } \\
\text { the emotional } \\
\text { part of being } \\
\text { a new parent }\end{array}$} & $\begin{array}{l}\text {-Basic routines } \\
\text { (i.e. changing } \\
\text { diapers) }\end{array}$ \\
\hline & & & $\begin{array}{l}\text {-Specific supports } \\
\text { for fathers to learn } \\
\text { about infant } \\
\text { temperament }\end{array}$ & & $\begin{array}{l}\text {-Child sickness } \\
\text { and medical } \\
\text { emergencies }\end{array}$ \\
\hline & & & $\begin{array}{l}\text {-Importance of } \\
\text { social }\end{array}$ & $\begin{array}{l}\text {-Frame as the } \\
\text { importance } \\
\text { of 'being }\end{array}$ & $\begin{array}{l}\text {-Critical } \\
\text { developmental } \\
\text { milestones }\end{array}$ \\
\hline
\end{tabular}

Page 14/21 
connectedness and relationships

-Focus on postpartum mental health for both mothers and fathers present' for their child
-Early bonding with the baby

-Supporting mothers through pregnancy and the postnatal period

-Developing healthy and stress-reducing habits for parents

Visit
timing/
associated
critical time
points

Some fathers

Prenatal: $30-34$
weeks
gestation $/ 3^{\text {rd }}$
trimester

Program initiation

N/A during pregnancy, when the decision to be an active parent occurs preferred program initiation before birth and some preferred after birth

Postnatal 1: 3-4 weeks of age/establish feeding practices

N/A

N/A

General support

-Concern that 3-4 weeks was too late for urgent needs with breastfeeding support during weeks 1-2

Postnatal 2: 3-4 N/A N/A
months of age/introduction of solids

-General support (considered an "impactful time")

-Some thought too early for introduction of solids

-Some suggested 3-4 months is too late because there is less uncertainty and fewer questions than during the first 1-2 months

\section{Intervention Design}

$\begin{array}{ll}\text { Visit } & \text { Prenatal: virtual } \\ \text { modality } & \text { visit } \\ & \text { Postnatal 1: } \\ & \text { home visit }\end{array}$

Postnatal 2: home visit

\section{Consider some} parents in target population cannot be in same place at the same time due to work or other conflicts

$\begin{array}{ll} & \text { Postnatal 2: } \quad \text { conflicts } \\ \text { home visit } & \end{array}$

-Home visits over virtual visits, particularly when first meeting dyads to establish rapport;
-Support for virtual prenatal visit

-Preferred inperson home visits for postnatal visits

\section{-Consider \\ family \\ preference}

$\begin{array}{ll}\begin{array}{l}\text { Delivery } \\ \text { mode }\end{array} & \text { Print/web/text- } \\ \text { based materials }\end{array}$

-Package intervention content in
-Web-based materials 
'bite-sized'

pieces

(videos, text

messaging,

and short

summaries)
-Mobile-based materials and printed information (especially postnatal period)

-Advanced notice of topics and after-visit summaries

\section{Engagement}

$\begin{array}{ll}\text { Engaging } & \text { Text messaging, } \\ \text { innovation } & \text { videos, mobile } \\ \text { participants } & \text { applications, } \\ & \text { electronic } \\ & \text { groups }\end{array}$

-Parent leaders

from community

partners to engage

fathers

-Dads in images for outreach

-Focus group

messages/images

with men and

women

-Use incentives/

material goods
-Use

community

health worker

model for

health coach

position to

address

potential

qualification

barriers for

applicants

-Connect with

professional

associations

and

community

organizations

(i.e. Fathers'

Uplift,

Nurturing

Fathers

Program,

Roca) to

further

advertise

positions.
N/A

N/A

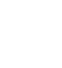




\begin{tabular}{|c|c|c|c|}
\hline CFIR Construct & $\begin{array}{l}\text { CFIR Construct } \\
\text { Definition }\end{array}$ & Themes & Illustrative Quotes \\
\hline $\begin{array}{l}\text { Relative } \\
\text { Advantage }\end{array}$ & $\begin{array}{l}\text { Stakeholders' } \\
\text { perception of the } \\
\text { advantage of } \\
\text { implementing the } \\
\text { intervention versus an } \\
\text { alternative solution. }\end{array}$ & $\begin{array}{l}\text { Perceived } \\
\text { advantages of the } \\
\text { proposed } \\
\text { intervention: } \\
\text { i. Unique father- } \\
\text { specific content } \\
\text { ii. Easy and } \\
\text { convenient delivery } \\
\text { iii. Individual } \\
\text { (versus group) } \\
\text { interaction and } \\
\text { instruction }\end{array}$ & $\begin{array}{l}\text { i. "I think having resources available for } \\
\text { dads might make it more-might normalize } \\
\text { more that dads are also involved in these } \\
\text { decisions about parenting. That might } \\
\text { increase dad involvement." } \\
\text { ii. "Getting more information and coming } \\
\text { to the house is much easier than figuring } \\
\text { out on your own where to go and who to } \\
\text { talk you to." } \\
\text { iii. "To me, why I like it is it separates me } \\
\text { from paying \$500 to be amongst a group } \\
\text { of } 14 \text { other people I don't know. That would } \\
\text { shut me down from being as open and } \\
\text { honest as I really want to be and need to } \\
\text { be to learn. That's a huge selling point in } \\
\text { my opinion. That one-on-one is very } \\
\text { beneficial." }\end{array}$ \\
\hline Complexity & $\begin{array}{l}\text { Perceived difficulty of } \\
\text { implementation, } \\
\text { reflected by duration, } \\
\text { scope, radicalness, } \\
\text { disruptiveness, } \\
\text { centrality, and } \\
\text { intricacy and number } \\
\text { of steps required to } \\
\text { implement. }\end{array}$ & $\begin{array}{l}\text { Perceived barriers of } \\
\text { the proposed } \\
\text { intervention: } \\
\text { i. Virtual visits: } \\
\text {. Technological } \\
\text { difficulties } \\
\text {. In-person } \\
\text { demonstration } \\
\text { preferred } \\
\text { ii. Home visits: } \\
\text { Intrusiveness } \\
\text { Tired/distracted } \\
\text { parents } \\
\text { iii. General } \\
\text { intervention: } \\
\text { Scheduling } \\
\text { conflicts } \\
\text { Disagreement } \\
\text { with information } \\
\text { presented }\end{array}$ & $\begin{array}{l}\text { i. "People have different levels of } \\
\text { comfort with technology and have } \\
\text { different devices." } \\
\text { "I can tell you what wouldn't be good } \\
\text { virtually is lactation support... Somebody } \\
\text { needs to show you. And I mean show your } \\
\text { wife, and you be there." } \\
\text { ii. "I think for some families they } \\
\text { probably feel uncomfortable with other } \\
\text { people in their home or telling them what } \\
\text { to do or what's best for their baby."; "at that } \\
\text { stage of three or four weeks, we're not able } \\
\text { to process, record, and make the } \\
\text { information useful because we are tired or } \\
\text { distracted." } \\
\text { iii. "Navigating any appointment ends } \\
\text { up being navigating my wife's schedule, } \\
\text { my schedule, the baby's, how the baby's } \\
\text { doing. All of a sudden, anything becomes a } \\
\text { little bit more complicated."; "I may have } \\
\text { different points of view of what they } \\
\text { believe is correct." }\end{array}$ \\
\hline
\end{tabular}

Design Quality \& Packaging
Perceived excellence

in how the intervention is bundled, presented, and assembled. i. Preference for pre-and postsummary of visit topics

ii. Mixed opinions regarding visit timing and structure

iii. Diverse

modalities of i. "I'm definitely the kind of person who want to receive the material ahead of time, I could actually read it, digest it, and ask questions instead of trying to absorb it during the visit."; "If there's a summary sheet of the key takeaways or key things to look out for, it's always helpful."

ii. "One visit is probably not enough and two is-yeah I think that's a perfect amount."; "Maybe the first two visits are more closely scheduled, like we'll say 4 
content delivery preferred

iv. List of intervention topics are appropriate, with a highlighted need for information on healthy eating, sleeping, and activity for babies and parents

weeks, and then at 7 weeks, and then another one at 18 to 20 weeks."

iii. "I like videos, absolutely, and a web page. Maybe even a quick text with someone on the other line."; "I would say printed information is good, but also maybe a link to the same type of information online would be helpful as well."

iv. 'You're hitting the nail on the head with every issue and period of the child's growth that I think parents fear...Any way you can prepare parents with information before that will definitely put their mind at ease."

Tailoring the intervention to specific parental needs encourages participation and engagement maintenance.
"In each of those virtual or in-person visits, there has to be one real aha takeaway that I feel like, 'Wow. I wouldn't have thought of that,' or, 'That really added something to my parenting toolbox,' rather than feeling like I was just getting some generic information."

Table 3: Father Engagement Interview Themes and Illustrative Quotes Mapped to CFIR Domains: Characteristics of Individuals 


\begin{tabular}{|c|c|c|c|}
\hline CFIR Construct & $\begin{array}{l}\text { CFIR Construct } \\
\text { Definition }\end{array}$ & Themes & Illustrative Quotes \\
\hline $\begin{array}{l}\text { Knowledge \& } \\
\text { Beliefs about } \\
\text { the } \\
\text { Intervention }\end{array}$ & $\begin{array}{l}\text { Individuals' } \\
\text { attitudes } \\
\text { toward and } \\
\text { value placed on } \\
\text { the intervention } \\
\text { as well as } \\
\text { familiarity with } \\
\text { facts, truths, } \\
\text { and principles } \\
\text { related to the } \\
\text { intervention. }\end{array}$ & $\begin{array}{l}\text { Fathers } \\
\text { perceive the } \\
\text { intervention } \\
\text { as needed } \\
\text { and valued, } \\
\text { based on: } \\
\text { i. Their } \\
\text { unique } \\
\text { challenges } \\
\text { preparing } \\
\text { for and } \\
\text { navigating } \\
\text { fatherhood } \\
\text { ii. Lack } \\
\text { of targeted } \\
\text { resources to } \\
\text { support } \\
\text { them with } \\
\text { challenges } \\
\text { and engage } \\
\text { in parenting }\end{array}$ & $\begin{array}{l}\text { i. "Where the mother is carrying the baby for nine } \\
\text { months, she's gonna get it, you know, it's just, like, a } \\
\text { natural reaction. Whereas the father's, like, oh my God, I } \\
\text { have a new child. What do I do?"; "Anything I receive on } \\
\text { becoming a dad, any advice. It just continues to get more } \\
\text { difficult." } \\
\text { ii. "So many things are geared towards moms. Even } \\
\text { when you read books, they are written for moms. It's very } \\
\text { clear. And that kind of makes you feel, as a father, like } \\
\text { excluded."; "I think having resources available for dads } \\
\text { might make it more-might normalize more that dads are } \\
\text { also involved in these decisions about parenting. That } \\
\text { might increase dad involvement." }\end{array}$ \\
\hline Self-efficacy & $\begin{array}{l}\text { Individual } \\
\text { belief in their } \\
\text { own } \\
\text { capabilities to } \\
\text { execute } \\
\text { courses of } \\
\text { action to } \\
\text { achieve } \\
\text { implementation } \\
\text { goals. }\end{array}$ & $\begin{array}{l}\text { Fatherhood } \\
\text { is a } \\
\text { rewarding } \\
\text { and } \\
\text { empowering } \\
\text { experience, } \\
\text { instilling a } \\
\text { sense of } \\
\text { purpose } \\
\text { and self- } \\
\text { efficacy to } \\
\text { provide for } \\
\text { the child } \\
\text { and partner. }\end{array}$ & $\begin{array}{l}\text {-"It's been a rewarding new experience watching a little } \\
\text { family member grow and mature and flourish." } \\
\text {-"I think the easiest thing is just being able to love my } \\
\text { daughter. It's my first baby, and everything is all new to } \\
\text { me, but it's - being a dad, I think just being able to love } \\
\text { and hold and comfort my daughter is the easiest thing." } \\
\text {-"What do I like most about being a dad? The feeling of } \\
\text { knowing that I have someone to come home to and what } \\
\text { I'm to doing to provide for them." } \\
\text {-"The most important thing is just obviously I want her to } \\
\text { be happy so whatever I can do to support her in that } \\
\text { sense, I'm gonna do it." }\end{array}$ \\
\hline $\begin{array}{l}\text { Other Personal } \\
\text { Attributes }\end{array}$ & $\begin{array}{l}\text { A broad } \\
\text { construct to } \\
\text { include other } \\
\text { personal traits } \\
\text { such as } \\
\text { tolerance of } \\
\text { ambiguity, } \\
\text { intellectual } \\
\text { ability, } \\
\text { motivation, } \\
\text { values, } \\
\text { competence, } \\
\text { capacity, and } \\
\text { learning style. }\end{array}$ & $\begin{array}{l}\text { Additional } \\
\text { personal } \\
\text { attributes } \\
\text { relevant to } \\
\text { the } \\
\text { intervention: } \\
\text { i. } \\
\text { Effects of } \\
\text { fatherhood } \\
\text { on father's } \\
\text { own health } \\
\text { ii. } \\
\text { Fathers' } \\
\text { perceived } \\
\text { Parenting } \\
\text { roles (day- } \\
\text { to-day child- } \\
\text { care, } \\
\text { emotional } \\
\text { support, }\end{array}$ & $\begin{array}{l}\text { i. "I have less time for gym or exercise. Not as much } \\
\text { time as I used to have."; "Taking care of yourself during } \\
\text { that period is often hard because you're just-that's a } \\
\text { secondary consideration, so I didn't sleep much. I was } \\
\text { eating at weird times. I was eating weird foods. Taking } \\
\text { care of yourself was harder than taking care of your kid, } \\
\text { actually." } \\
\text { ii. "Parenting is a two-person job. Just 'cause you're } \\
\text { wife's breastfeeding doesn't mean you're not involved in } \\
\text { the nutrition of your child. Yeah, the earlier you're involved, } \\
\text { the happier you'll be."; "Just making sure that she's } \\
\text { healthy, so making sure that she's developing, getting } \\
\text { bigger and eating and monitoring to make sure she } \\
\text { doesn't have a fever."; "I do a lot of the day-to-day on the } \\
\text { home, everything around the home, cooking, } \\
\text { cleaning...Mine's more home and home maintenance, day- } \\
\text { to-day maintenance."; "A lot of it was just being proactive } \\
\text { on all sorts of responsibilities more broadly than baby } \\
\text { care, doing shifts as night so Mom can get some sleep." }\end{array}$ \\
\hline
\end{tabular}




\section{Figures}

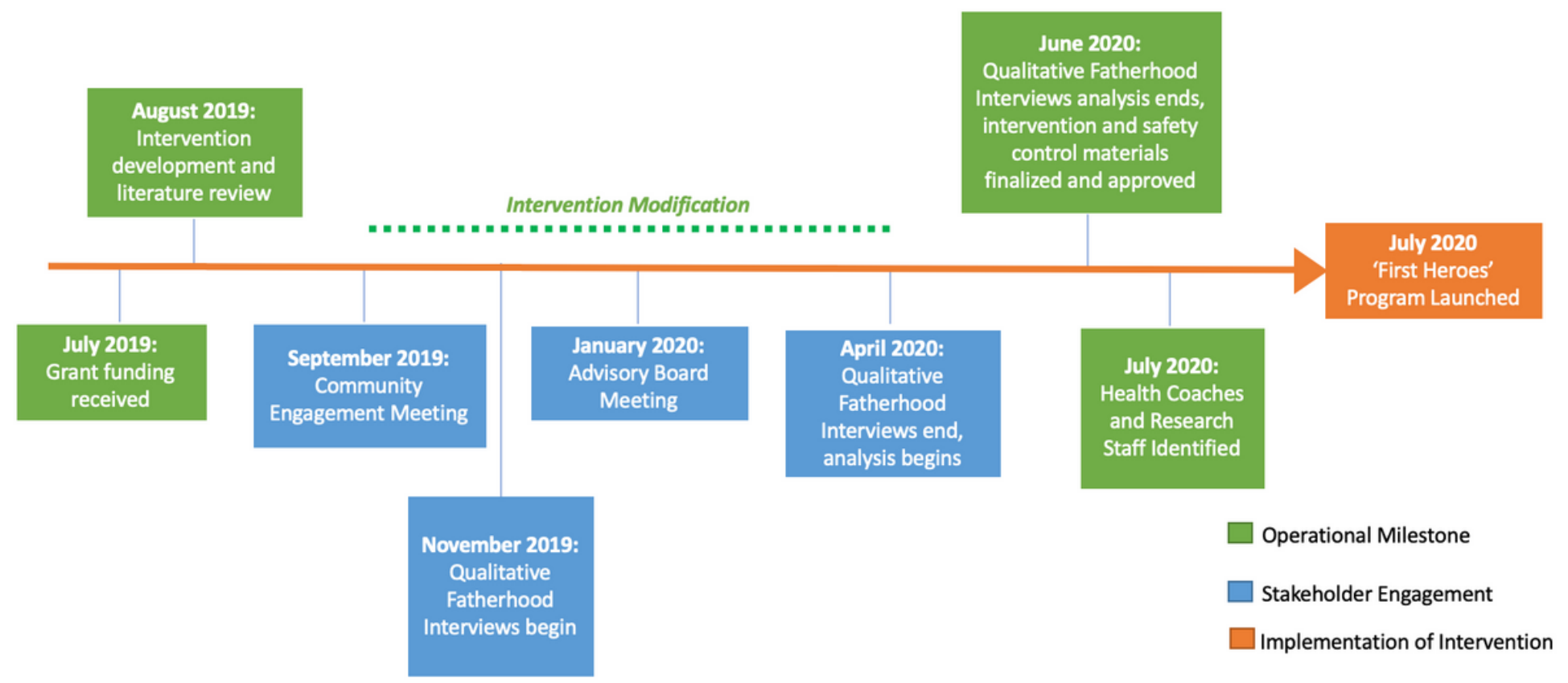

\section{Figure 1}

Process of Stakeholder Engagement in Design of the "First Heroes" Intervention

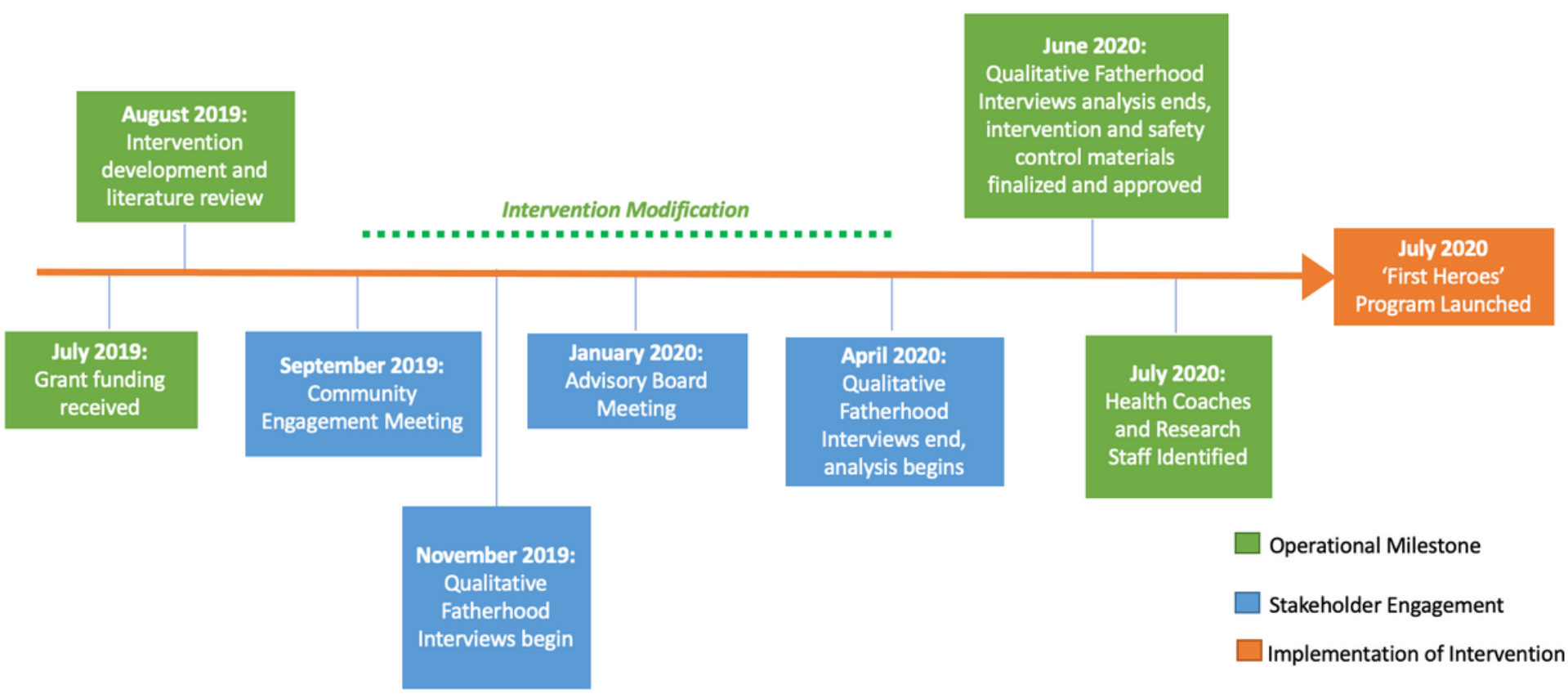

Figure 1 
Process of Stakeholder Engagement in Design of the "First Heroes" Intervention

Page 21/21 